\title{
SINGULAR VECTOR FOR A SHALLOW WATER MODEL
}

\author{
Chularat Srikul and Dussadee SuKawat \\ Department of Mathematics, Faculty of Science, \\ King Mongkut's University of Technology Thonburi, \\ Bangkok 10140, Thailand. \\ chularat.s@hotmail.com; dusadee.suk@kmutt.ac.th
}

\begin{abstract}
The atmosphere is a chaotic dynamical system, small errors in the initial condition of an atmospheric model can lead to growing errors in the forecast. In order to reduce uncertainty in the forecast which occur from using only one initial condition from many possible initial conditions, more initial conditions are required. In practice, however, there is only single observation available for the initial condition. In this paper the singular vector has been applied to a single level shallow water model of the atmosphere to generate more initial conditions from one observation.

ABSTRAK: Atmosfera ialah satu sistem dinamik yang huru-hara. Kesilapan kecil dalam kondisi awal model atmosfera boleh membawa kepada kesilapan yang semakin meningkat di dalam ramalan. Dalam usaha untuk mengurangkan ketidakpastian dalam ramalan yang berlaku dari menggunakan hanya satu kondisi awal, lebih banyak kondisi awal diperlukan. Secara praktikalnya, walau bagaimanapun, hanya terdapat satu pemerhatian yang sedia ada untuk kondisi awal. Kajian ini menerangkan vektor tunggal telah digunakan untuk model air cetek tahap atmosfera untuk menghasilkan lebih banyak kondisi awal dari satu pemerhatian.
\end{abstract}

KEYWORDS: shallow water model; tangent linear model; adjoint linear model; singular vector

\section{INTRODUCTION}

The results from numerical models of the atmosphere can sometimes contain large errors. A reason for this lies in the nature of the atmosphere in which very small errors in the initial conditions can lead to large errors in the forecast. Implying a perfect forecast system cannot be created because every detail of the initial state of the atmosphere cannot be observed. To cope with this uncertainty, ensemble forecasting which is a collection of difference forecasts and all valid at the same forecast time is applied. Kalney [1] discussed a simple model by using the singular vector technique to create ensemble forecasting. Wei and Frederiksen [2] used lyapunov vectors and singular vectors to examine errors growth and predictability in atmospheric models. Khade and Hansen [3] found that the singular error growth in the most parts of the attractor is rapid, in that errors can grow almost by a factor of 3 over one step.

In this paper the singular vector method is applied to a linearized shallow water model of the atmosphere to generate more initial conditions from the initial data.

\section{METHODOLOGY}

\subsection{The Shallow Water Model}


The shallow water model is a simplified version of the equations of motion. The momentum, hydrostatic and continuity equations are given below [4].

$$
\begin{gathered}
\frac{d u}{d t}-f v+\frac{1}{\rho} \frac{\partial p}{\partial x}=0 \\
\frac{d v}{d t}+f u+\frac{1}{\rho} \frac{\partial p}{\partial y}=0 \\
\frac{\partial p}{\partial z}+\rho g=0 \\
\frac{\partial u}{\partial x}+\frac{\partial v}{\partial y}+\frac{\partial w}{\partial z}=0
\end{gathered}
$$

where $\mathrm{r}$ is the density of the atmosphere, $p$ is the pressure, $f$ is the Coriolis parameter which is given by $f=2 \Omega \sin \theta$ ( $\Omega$ is the angular velocity of the earth, $\theta$ is the latitude), $g$ is the acceleration due to gravity and $u, v$ and $w$ are the speed of fluid in the $x, y$ and $z$ directions, respectively.

The shallow water model consists of a set of three equations with three dependent variables $(u, v, \phi)$.

$$
\begin{aligned}
& \frac{d u}{d t}-f v+g \frac{\partial \phi}{\partial x}=0 \\
& \frac{d v}{d t}+f u+g \frac{\partial \phi}{\partial y}=0 \\
& \frac{d \phi}{d t}+\phi \nabla_{H} \cdot V=0
\end{aligned}
$$

where $\phi$ is the geopotential height.

The vertical velocity does not appear explicitly. The total time derivative is given by

$$
\frac{d}{d t}=\frac{\partial}{\partial t}+u \frac{\partial}{\partial x}+v \frac{\partial}{\partial y}
$$

\subsection{The Singular Vector Method}

Singular vector (SV) method is explained here according to Kalney [1]. The initial conditions for the ensemble prediction system (EPS) are created to represent the uncertainties in the operational analysis. They are made by adding to the operation analysis perturbations which produce the fastest growth during the first stage of the forecast period, defined using the singular vector technique. The purpose is to find those perturbations to a given initial state which grow most rapidly [5]. The calculation of the singular vectors is the tangent - linear version of the full (non -linear) operational forecast 
IIUM Engineering Journal, Vol. 12, No. 5, 2011: Special Issue -1 on Science and Ethics in Engineering

Srikul and Sukawat

model. A second model, the adjoint of the tangent linear model is also needed in the singular vector calculation.

a) The Tangent Linear Model Method (TLM)

Consider a non linear model

$$
x(t)=M\left[x\left(t_{0}\right)\right]
$$

where $x\left(t_{0}\right)$ is the state at the initial time and $x(t)$ is the state at time $t$ and $M$ is the time integration of the numerical scheme from the initial condition to time $t$.

The tangent linear model (TLM) is defined such that

$$
L=\frac{\partial M}{\partial x}
$$

where $L$ is the tangent linear model of $M$.

So the TLM evolves a perturbation in time;

$$
y(t)=L\left(t_{0}, t\right) y\left(t_{0}\right)
$$

where $y\left(t_{0}\right)$ is the perturbation state at the initial time $t=0$ and $y(t)$ is the perturbation state at time $t$ [3].

b) The Adjoint of the Tangent Linear Model

The adjoint tangent linear model is the transpose of the tangent linear model.

\section{c) The Singular Vector}

Singular value decomposition theory indicates that for any matrix $L$ there exist two orthogonal matrices $U, V$ such that

$$
U^{T} L V=S
$$

where $S=\left[\begin{array}{cccc}\sigma_{1} & 0 & \ldots & 0 \\ 0 & \sigma_{2} & \ldots & 0 \\ \vdots & \vdots & & \vdots \\ 0 & 0 & \ldots & \sigma_{n}\end{array}\right]$ and $U U^{T}=I, V V^{T}=I$

$S$ is a diagonal matrix whose elements are the singular values of $L$ and $I$ is the identity matrix.

So that

$$
L v_{i}=\sigma_{i} u_{i}
$$

The vector $\left(v_{1}, \ldots, v_{n}\right)$ are the right singular vectors of $L$.

Consequently

$$
L^{T} u_{i}=\sigma_{i} v_{i}
$$


The vector $\left(u_{1}, \ldots, u_{n}\right)$ are the left singular vectors of $L$.

Therefore, the initial singular vectors can be obtained as the eigenvectors of $L^{T} L$, the final singular vectors can be obtained as the eigenvectors of $L L^{T}$ and eigenvalues are the squares of the singular values.

Consider a basic trajectory

$$
\begin{aligned}
& y\left(t_{0}\right)=\sum_{i=1}^{n}<y\left(t_{0}\right), v_{i}>v_{i} \\
& y\left(t_{1}\right)=\sum_{i=1}^{n}<y\left(t_{1}\right), u_{i}>u_{i} .
\end{aligned}
$$

Applying the tangent linear model $L$ in (11) and (15) and rearrange in the form

$$
<y\left(t_{1}\right), \sigma_{i} u_{i}>=<y\left(t_{0}\right), v_{i}>
$$

Applying the adjoint of the tangent linear model $L^{T}$ in (11) and (16)

$$
<y\left(t_{0}\right), \sigma_{i} v_{i}>=<y\left(t_{1}\right), u_{i}>
$$

Applying $L^{T} L$ by running tangent linear model forward in time, and then the adjoint backward in time.

$$
<y\left(t_{1}\right), \sigma_{i} u_{i}>=\sigma_{i}^{2}<y\left(t_{0}\right), v_{i}>
$$

\subsection{The Numerical Method of the Shallow Water Model}

The forward in time center in space finite difference method is used to solve the shallow water equations on Arakawa - A grid.

a) Discretized the Shallow Water Model

$$
\begin{array}{r}
u_{i}^{j+1}=u_{i}^{j}-\alpha u_{i}^{j}\left(u_{i+1}^{j}-u_{i-1}^{j}\right)-\beta v_{i}^{j}\left(u_{i+1}^{j}-u_{i-1}^{j}\right)+\Delta t f v_{i}^{j}-\alpha g\left(\phi_{i+1}^{j}-\phi_{i-1}^{j}\right) \\
v_{i}^{j+1}=v_{i}^{j}-\alpha u_{i}^{j}\left(v_{i+1}^{j}-v_{i-1}^{j}\right)-\beta v_{i}^{j}\left(v_{i+1}^{j}-v_{i-1}^{j}\right)-\Delta t f u_{i}^{j}-\beta g\left(\phi_{i+1}^{j}-\phi_{i-1}^{j}\right) \\
\phi_{i}^{j+1}=\phi_{i}^{j}-\alpha u_{i}^{j}\left(\phi_{i+1}^{j}-\phi_{i-1}^{j}\right)-\beta v_{i}^{j}\left(\phi_{i+1}^{j}-\phi_{i-1}^{j}\right)-\alpha \phi_{i}^{j}\left(u_{i+1}^{j}-u_{i-1}^{j}\right)-\beta \phi_{i}^{j}\left(v_{i+1}^{j}-v_{i-1}^{j}\right)
\end{array}
$$

where $\alpha=\frac{\Delta t}{2 \Delta x}, \beta=\frac{\Delta t}{2 \Delta y}$

\section{b) Initial Condition}

For this research the initial conditions are

$$
\begin{gathered}
u_{0}=-g \frac{d \phi}{d y} / f \\
v_{0}=g \frac{d \phi}{d x} / f
\end{gathered}
$$




$$
\phi_{0}=\phi W a v e+\phi B a r+\phi R e f
$$

where

$$
\begin{aligned}
& \phi \text { Wave }=\phi A m p * \sin (2 * p i * m x * X / L x) * \cos (m y * p i *(Y-y 0) / L y) \\
& \phi B a r=-\left(\frac{u B a r}{g}\right) *\left(f 0 *(Y-y 0)+0.5 * \operatorname{beta}^{*}(Y-y 0)^{2}\right) \phi \operatorname{Ref}=5500 \text { is the constant reference }
\end{aligned}
$$
geopotential height, $\phi A m p=500$ is the constant amplitude geopotential height. $m x=1$ and $m y=1$ are wave numbers in $\mathrm{x}$ and $\mathrm{y}$ directions, respectively. $L x$ and $L y$ are channel lengths in $\mathrm{x}$ and $\mathrm{y}$ directions, respectively.

\section{c) Boundary Condition}

The boundary condition in the east-west direction is a cyclic boundary and the north-south direction is an updated boundary.

\section{d) Experiment}

The domain of the model is $32 \times 10^{6}$ meters in $\mathrm{x}$-direction and $8 \times 10^{6}$ meters in $y$-direction, grid size in $x$-direction is $8 \times 10^{5}$ meters and grid size in $y$-direction is $8 \times 10^{5}$ meters, time step is 600 seconds. The output interval from the forecast model is 6 hours.

\subsection{Step of Calculation the Singular Vector}

Step1: The tangent linear model

From (10) for the shallow water model is calculated as

$$
L=\frac{\partial M_{i}}{\partial U}=\left[\begin{array}{ccc}
\frac{\partial^{2} u}{\partial u \partial t}+u \frac{\partial^{2} u}{\partial u \partial x}+\frac{\partial u}{\partial x}+v \frac{\partial^{2} u}{\partial u \partial y} & \frac{\partial u}{\partial y} \cdot \frac{\partial v}{\partial y}-f & g \frac{\partial^{2} z}{\partial \partial \partial x} \\
\frac{\partial v}{\partial x}+f & \frac{\partial^{2} v}{\partial \nu \partial t}+u \frac{\partial^{2} v}{\partial \nu \partial x}+v \frac{\partial^{2} v}{\partial v \partial y}+\frac{\partial v}{\partial y} & g \frac{\partial^{2} z}{\partial \partial \partial y} \\
\frac{\partial^{2}}{\partial x}+z \frac{\partial^{2} u}{\partial u \partial x} & \frac{\partial z}{\partial y}+z \frac{\partial^{2} v}{\partial v \partial y} & \frac{\partial^{2} z}{\partial \partial \partial t}+u \frac{\partial^{2} z}{\partial z \partial x}+\frac{\partial^{2} z}{\partial \partial \partial y}+\frac{\partial u}{\partial x}+\frac{\partial v}{\partial y}
\end{array}\right]
$$

The discretized form of (24) is then used to calculate the tangent linear model at each of grid point.

Step2: The adjoint linear tangent model is the transpose of the linear tangent model.

Step3: Calculating the singular vector and singular value from (13) and (14) have to be repeated many times to generate several perturbations.

The maximum norm of perturbations and minimum norm of perturbations are then added to the initial condition to generate the new initial conditions.

In this paper the norm of vector is defined as

$$
\left\|y_{i}\right\|=\sqrt{|u|^{2}+|v|^{2}+|\phi|^{2}}
$$

For example, at a point where the initial pertubations $y\left(t_{0}\right)=\left[\begin{array}{r}-0.1871 \\ 0.4344 \\ 277.2987\end{array}\right]$ a single cycle of $L$ and $L^{T}$ transformations result in $y\left(t_{1}\right)=\left[\begin{array}{l}1.7712 \\ 0.0629 \\ 3.8762 \mathrm{e}^{-10}\end{array}\right]$. 


\section{RESULTS AND DISCUSSION}

\subsection{Result of the shallow water model}

Figure 1 shows the velocity and geopotential field following (21) and (22). Figure 2 shows the result of forecast at 6 hours.

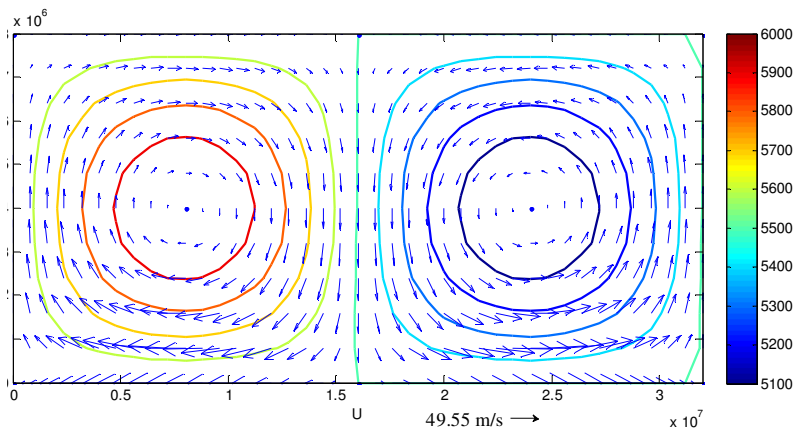

Fig. 1: The initial state of the velocity field (vectors) and geopotential heights (contour lines).

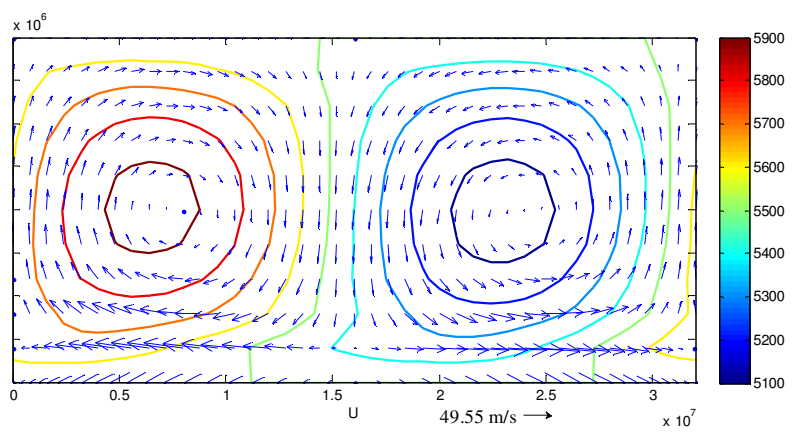

Fig. 2: The forecast state of the velocity field (vectors) and geopotential heights (contour lines) at 6 hours.

Table 1:

Examples of singular vectors and singular values of perturbation at grid point $(2,3)$.

\begin{tabular}{|c|c|c|c|c|}
\hline \multirow{2}{*}{ State } & \multicolumn{3}{|c|}{ Singular vector } & \multirow{2}{*}{ Perturbation } \\
\cline { 2 - 4 } & $\mathbf{v}_{\mathbf{1}}$ & $\mathrm{v}_{2}$ & $\mathrm{v}_{3}$ & \\
\hline \multirow{2}{*}{$\mathrm{I}$} & {$\left[\begin{array}{l}0.859 \\
-0.511 \\
-6.907 \mathrm{e}^{-5}\end{array}\right]$} & {$\left[\begin{array}{l}0.512 \\
0.859 \\
4.979 \mathrm{e}^{-5}\end{array}\right]$} & {$\left[\begin{array}{c}3.386 \mathrm{e}^{5} \\
-7.813 \mathrm{e}^{-5} \\
0.999\end{array}\right]$} & {$\left[\begin{array}{c}-0.187 \\
0.434 \\
277.298\end{array}\right]$} \\
\hline $\mathrm{N}$ & 1 & 1 & 1 & 277.2992 \\
\hline $\mathrm{F}$ & {$\left[\begin{array}{c}0.221 \\
-0.131 \\
-1.778 e^{-5}\end{array}\right]$} & {$\left[\begin{array}{l}1.598 \\
2.683 \\
0.0001\end{array}\right]$} & {$\left[\begin{array}{c}2.422 e+7 \\
-5.589 e+7 \\
7.154 e+7\end{array}\right]$} & {$\left[\begin{array}{l}1.771 \\
0.063 \\
3.877 e^{-10}\end{array}\right]$} \\
\hline $\mathrm{N}$ & 0.2574 & 3.12273 & $7.154 \mathrm{e}+11$ & 1.77234 \\
\hline
\end{tabular}


In Table 1, I denotes the initial state of singular vector, $\mathrm{F}$ is the final state of singular vector and $\mathrm{N}$ is the norm of singular vector. The singular vector at the grid point in Table 1 can be represented as vectors as shown in Fig. 3-5.

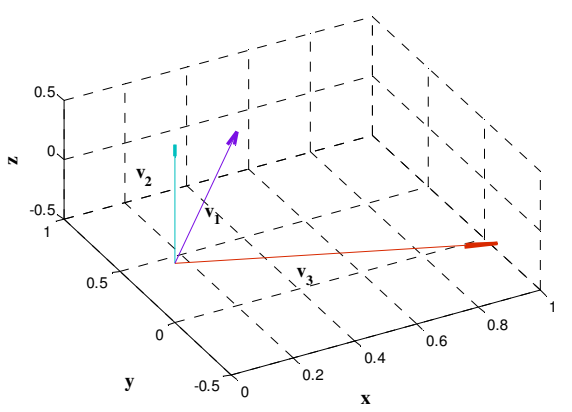

Fig. 3: $\mathrm{V}_{\mathrm{i}}$ are the initial time singular vectors; $\mathrm{x}, \mathrm{y}$ and $\mathrm{z}$ axes represent $\mathrm{u}, \mathrm{v}$, and $\phi$, respectively.

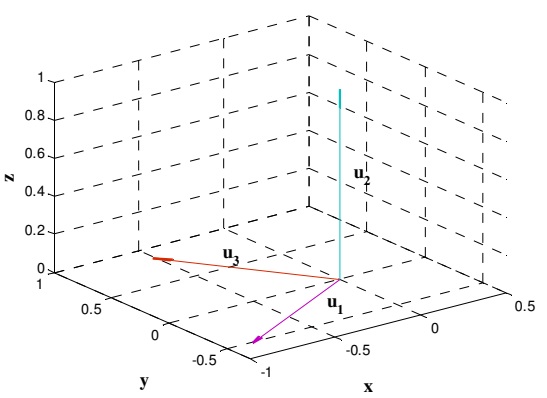

Fig. 4: $U_{i}$ are the final time singular vectors with $\sigma_{1}=0.2574, \sigma_{2}=3.1227$ and $\sigma_{3}=7.1537 \mathrm{e} 11$; $\mathrm{x}, \mathrm{y}$ and $\mathrm{z}$ axes represent $\mathrm{u}, \mathrm{v}$, and $\phi$, respectively.

The tangent linear model stretches (or shrinks) and rotates each of the perturbation vectors. At each step the initial state can be transformed to the final state as shown in Fig. 3. Figure 4 shows the adjoint tangent linear model stretches (or shrinks) and rotats for each of the perturbation vectors.

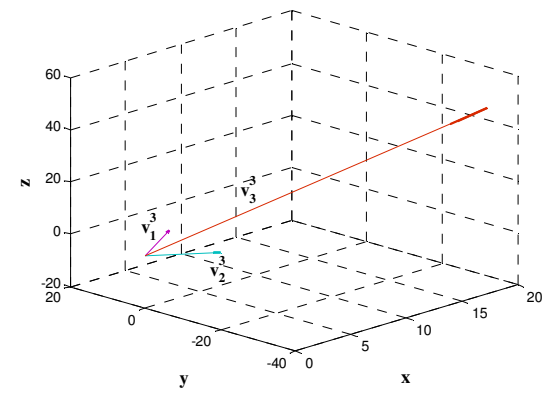

Fig. 5: $\mathrm{v}_{\mathrm{i}}$ are the final time singular vectors with

$$
\sigma_{1}^{2}=0.066, \sigma_{2}^{2}=9.7512 \text { and } \sigma_{3}^{2}=5.1175 \mathrm{e}+23 \text {; }
$$

$x, y$ and $z$ axes represent $\mathrm{u}, \mathrm{v}$, and $\phi$, respectively. 


\section{CONCLUSION}

In this paper a singular vector is applied at a grid point in linearized shallow water wave model. A single vector transformation results in a significant the change in the norm of the initial perturbation. The method can be used to generate initial states to an ensemble shallow water model for ensemble forecasts.

\section{ACKNOWLEDGEMENTS}

The first author would like to thank Rajamangala University of Technology Tawan-ok (RMUTTO) and Mathematics Department of King Mongkut's University of Technology Thonburi (KMUTT) for the financial support.

\section{REFERENCES}

[1] Kalnay E., 2003, Atmospheric Modeling Data Assimilation and Predictability, Cambridge University Press, UK., vol. 341, pp.1-2.

[2] Mozheng Wei and Jorgen S. Frederiksen., 2000, "Iterative methods for Lyapunov vectors and singular vectors and atmospheric predictability," ANZIAM J., vol. 42, pp. 1501-1519.

[3] V. M. Khade and J. A. Hansen., 2004, "State dependent predictability: Impact of uncertainty dynamics, uncertainty structure and model inadequacies," Nonlinear Processes in Geophysics, vol. 11, pp. 351-362.

[4] Holton J. R., 2004, Introduction to Dynamic Meteorology, $4^{\text {th }}$ ed., Elsevier Inc., UK., pp. 188-219

[5] L. Magnusson, E. Kallen, and J. Nycander, 2008, "Initial state perturbations in ensemble forecasting," Nonlinear Processes in Geophysics, vol. 15, pp. 751-759. 